\title{
Obstructive sleep apnea, CPAP treatment and bradyarrhythmias: close relationship or simple coincidence? A brief review based on case series
}

\author{
Nicola Vitulano \\ Department of Cardiovascular Disease, Catholic University of the Sacred Heart, Rome, Italy.
}

Correspondence: Nicola Vitulano. Address: Department of Cardiovascular Disease, Catholic University of the Sacred Heart, Largo A. Gemelli 1, 00168, Rome, Italy. Email: nicola.vitulano@gmail.com

Received: May 8, 2014

DOI : $10.5430 /$ crim.v2n1p62
Accepted: July 4, 2014

URL: http://dx.doi.org/10.5430/crim.v2n1p62

\begin{abstract}
During the last decades the interest about sleep-related disordered breathing (SDB) has increased, due principally to several studies showing their involvement in cardiovascular disease. The key role of the sleep in one's life is linked to its effects on the cardiovascular and respiratory systems. Sleep apnea syndromes (SAS) are characterized by several nightly apneic events; during these events there is the absence or a considerable reduction of the airflow with consequent oxyhemoglobin desaturation and arousal, causing microawakening and sleep fragmentation that represent, along with hypoxemia, important harmful triggers on the cardiovascular system. The impact of sleep apnea in patients with cardiovascular disease is relevant to worsen the cardiac clinical features. For the clinician it is the important to know the sleep apnea syndrome and its impact on cardiac patients regarding its negative effects; in fact, in selected patients sleep apnea should be detected, above all regarding the positive effects of its treatment.
\end{abstract}

\section{Keywords}

Sleep apnea syndrome, Bradyarrhythmias, Continuous positive airway pressure, Obstructive sleep apnea, Sinusal pause

\section{Introduction}

The importance of sleep in human life is well known for its important cardiorespiratory, metabolic and neurological physiologic consequences. Thus it is important to recognize SDB and obviously to try to treat. Among them SAS represents a remarkable part regarding its prevalence and physiopathological impact. By recent study it is found a raising prevalence of SDB in the general population: moderate to severe SDB affect $10 \%$ of $30-49$-year-old men, $17 \%$ of 50-70-year-old men, $3 \%$ of 30-49-year-old women and 9\% of 50-70 year-old women ${ }^{[1]}$.

The studies during last decades throw light on the importance of the involvement of sleep apnea in the cardiovascular disease. In the field of arrhythmias findings from cross-sectional and observational studies and recent reviews suggest a high prevalence of cardiac arrhythmias in patients with SAS. Probably structural and electrical remodelling of the cardiac walls due to excessive negative intrathoracic pressure and increased sympathetic activation triggered by apneic events may increase the susceptibility to arrhythmia in SAS patients. Observational studies reported a higher prevalence of bradyarr- 
hythmia in patients affected by sleep apnea syndrome; preliminary evidence supported the hypothesis that apneic events are associated with bradicardics events ${ }^{[2]}$.

\section{Aim and methodology}

Based on this backgroud we decided to assess the possible relationship between SAS and bradyarrhythmias. Through data collected in the clinical practice, patients showing bradicardic events and/or sinusal pauses to $24 \mathrm{~h}$ - Holter monitor were selected regarding high probability for SAS (anamnesis of sleep history, BMI, Epworth Sleepiness Scale) and underwent to a cardio-respiratory sleep study establishing a diagnosis of sleep apnea syndrome with prevalent obstructive sleep apnea. The patients were treated by continuos positive airway pressure (CPAP) for the obstructive nightly apnea and then the effects of this treatment on cardiac rhythm was monitored by an additional 24h-Holter-ECG. This short case series represents a futher evidence of the relationship between obstructive sleep apnea and cardiac disturbances in term of bradicardic events.

\section{Case series}

\subsection{Clinical case 1}

A 51-years-old man was referred to our hospital by general pratictioner for a cardiac evaluation regarding the symptomatology of daytime asthenia and its cardiovascular risk factors such as mild hypertension, hypercholesterolemia and obesity. ECG, echocardiogram and ergometric test did not reveal abnormal features. A 24-h Holter monitoring documented sinus rhythm with 2 bradycardics events, 26 sinusal pauses (above all during the night). Regarding to anthropometric patient's features and after a careful anamnesis about daytime tiredness, we administered an Epworth questionnaire (with total score of 10) and we performed cardiorespiratory sleep study embracing an 8-hour period. A total of 35.3 obstructive sleep apneas (OSA), 7.6 central sleep apneas (CSA) 16.4 mixed sleep apneas and 23.6 hypopneas per hour were detected, with an Apnea-Hypopnea Index (AHI) of 82,9/hour. Mean and minimum SpO2 were 93\% and 75\%, respectively. The Oxygen desaturation Index (ODI) was 30/hour. Severe sleep apnea syndrome was eventually diagnosed.

\subsection{Clinical case 2}

A 69-years-old woman was admitted into the Cardiology Unit for dyspnoea for mild efforts (class NYHA II), nightly events of dyspnea and recent onset of daytime asthenia. ECG and echocardiogram did not document pathological features and the ergometric test was negative for myocardial ischaemia. A 24-h Holter monitoring showed sinus rhythm with 31 bradycardics events and 9 sinusal pauses. After a careful anamnesis about nocturnal events of dyspnoea and daytime tiredness, with a score of Epworth questionnaire of 8, we performed cardiorespiratory sleep study embracing a 6-hour period and showing an apnoea-hypopnea (AHI) of 30/h with a prevalent obstructive component and hypoxemia under $90 \%$ for about $20 \%$ of sleeping time and severe hypoxemia (value under $80 \%$ ) for $2 \%$ of the sleeping time with minimum $\mathrm{SpO}_{2}$ of $77 \%$, with a conclusive diagnosis of obstructive sleep apnoea syndrome.

\subsection{Clinical case 3}

A 72-years-old man with a history of chronic atrial fibrillation was referred to our Cardiology Unit for self-reported lipothymic events, one of them during driving. ECG showed atrial fibrillation with ventricular rate of 65 beat per minute; echocardiogram and ergometric test documented normal findings (except moderate mitral regurgitation with mild left atrial enlargement). A 24h-Holter monitoring evidenced atrial fibrillation with 6 pauses (max $2.6 \mathrm{sec}$ at 06:16 during sleep). The patients was underwent also a neurological assessment with EEG showing a trace within normal range with diffuse slowing traits related to somnolence. Thus, after an analyzed anamnesis about the circumstances of some events, snoring, not refresh sleep and an Epworth Sleepness Scale score of 12 he was underwent to cardiorespiratory sleep study. The study embraced a 7-hour period. A total of 10.7 OSA, 0.2 CSA, 1.8 mixed sleep apneas and 4.4 hypopneas per hour 
were detected, with an Apnea-Hypopnea Index (AHI) of 17.1/hour. Mean and minimum $\mathrm{SpO}_{2}$ were 94\% and 76\%, respective; thus matching the diagnostic criteria obstructive for sleep apnea syndrome (OSAS).

\subsection{Treatment of obstructive sleep apnea and 24h Holter monitoring}

The patients started on therapy with continuous positive airway pressure (CPAP) for the treatment of obstructive sleep apnea syndrome. During hospitalization a nocturnal saturimetry confirmed its effectiveness documenting absence of clinically relevant nocturnal desaturation. To monitor the potential effects of CPAP therapy on cardiac rhythm we perfomed 24-h Holter monitoring after a week of therapy with CPAP showing for the three patients an increase of mean heart rate, but above all the absence of pauses (see Table 1). The patients were discharged with indication to keep on CPAP therapy.

Table 1. Patients' features

\begin{tabular}{|c|c|c|c|c|c|c|c|c|}
\hline \multicolumn{9}{|l|}{ Baseline } \\
\hline Clinical Case & Age & Gender & AHI & Basal Rhythm & $\begin{array}{l}\text { Mean Heart } \\
\text { Rate }\end{array}$ & FC min & $\begin{array}{l}\text { Episodes of } \\
\text { bradycardia }\end{array}$ & Pauses \\
\hline Patient 1 & 51 & M & 83 & sinusal & 70 & 36 & 2 & 26 \\
\hline Patient 2 & 69 & $\mathrm{~F}$ & 30 & sinusal & 73 & 45 & 31 & 9 \\
\hline Patient 3 & 72 & M & 17 & atrial fibrillation & 65 & 35 & 0 & 6 \\
\hline \multicolumn{9}{|c|}{ After CPAP Therapy } \\
\hline Clinical Case & Age & Gender & AHI & Basal Rhythm & $\begin{array}{l}\text { Mean Heart } \\
\text { Rate }\end{array}$ & FC min & $\begin{array}{l}\text { Episodes of } \\
\text { bradycardia }\end{array}$ & Pauses \\
\hline Patient 1 & 51 & M & 83 & sinusal & 73 & 39 & 8 & 0 \\
\hline Patient 2 & 69 & $\mathrm{~F}$ & 30 & sinusal & 75 & 49 & 0 & 0 \\
\hline Patient 3 & 72 & M & 17 & atrial fibrillation & 68 & 40 & 0 & 0 \\
\hline
\end{tabular}

\section{Discussion}

The rising interest about SDB syndromes is related to the importance of sleep in the human life. Sleep is physiologic phenomenon characterized by reduction of motor activity and response to the stimulus, presence of stereotyped position, relatively quick reversibility, delay vegetative life ${ }^{[3]}$. These physiologic changes have the objective to create a quiescent cardiovascular, respiratory and metabolic state in order to restore the human body. SDB modify this delicate balance with consequences on cardiovascular system also during daytime. Among the SDB obstructive sleep apnoea represents the most common form, but frequently under diagnosed. High prevalence of sleep apnoea represents a social problem both for its symptoms in daytime and above all for its emerging and confirmed association with cardiovascular morbidity. Apnea is defined as the interruption of the airflow or a drop in the peak airflow signal excursion by $>90 \%$ of pre-event baseline for more than 10 seconds associated with oxygen desaturation and arousal detected at the electroencephalogram (EEG). Hypopnea is defined as a reduction in breathing amplitude more than $30 \%$ of pre-event baseline associated to a desaturation of $3 \%$ or an arousal. It is possible distinguish the apnoic events in obstructive when the airflow cessation is accompanied by a thoracic-abdominal effort to overtake the collapse of upper airways, central, due to central disfunction and characterized by the absence of thoracic-abdominal movements, and mixed, with a starting central phase and last phase with obstructive features ${ }^{[4]}$ (see Figure 1 ). This condition of complete or partial obstruction of upper airway repeated during whole night provokes a fragmented sleep with microawakenings and disturbance of neurovegetative system due continuous arousal ${ }^{[5]}$. These harmful changes have a clinical repercussion with symptoms such as snoring, unrefreshing sleep, witnessed apnea, awakenings with choking, morning headache, lack of concentration and daytime somnolence. The diagnosis of SAS should not be made without an instrumental assessment in a sleep laboratory. The gold standard for diagnosis is polysomnography, a complete monitoring of several parameters such as recording of brain waves (eeg), electromyogram, electrocardiogram (ecg), thoracic and abdominal movements, nasal and oral airflow and pulse oxymetric ${ }^{[4]}$. However, the use of more easily available portable monitors for the detection of sleep apnea in cardio- 
vascular patients has been shown to be an acceptable option, especially if a relatively high pre-test probability is present. The complex pathways underlying the relationship between cardiovascular disease and OSAS are still poorly understood. Probably such as for other condition, there is a multifactioral process involving hemodynamic and structural cardiac changes, hypoxic trigger, flogosis impact and disregulation in sympathetic activity.

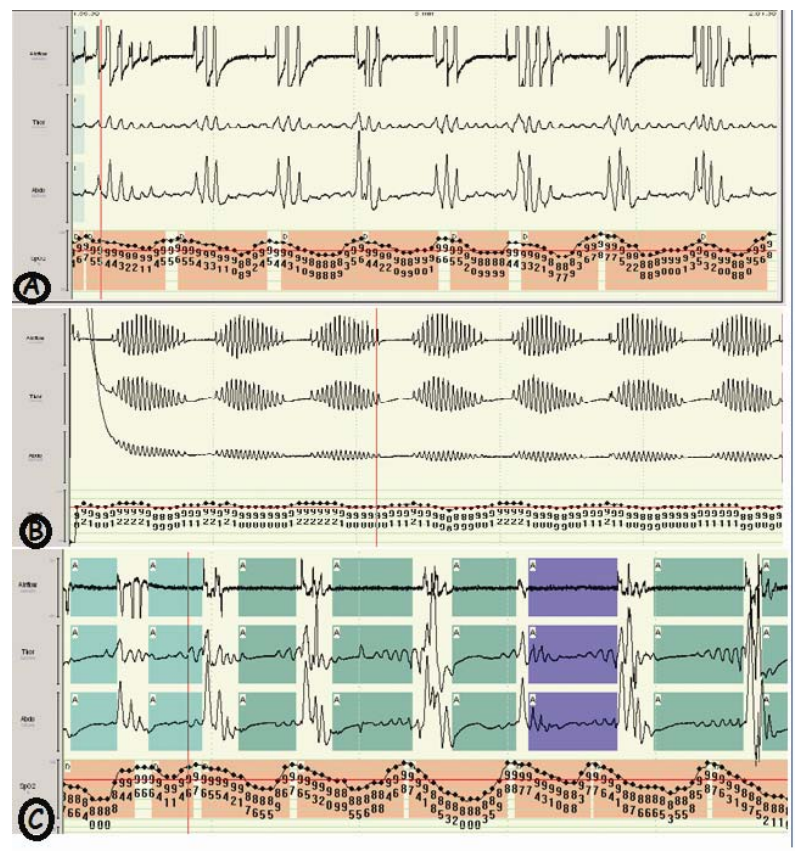

Figure 1. Through the report of the cardiorespiratory sleep study it is possible to distinguish different episodes of sleep apnoea, typically classified as obstructive (A), central (B) or mixed (C), regarding the criterion of the concomitant presence of efforts to breathe through the registration of thorax and abdominal movement in the first one or the absence of these movements in the second one. Mixed sleep apnoea are characterized by a starting phase with central features and last phase with obstructive component.

\subsection{Mechanisms linking OSA to arrhythmias}

In patients with obstructive sleep apnea cardiac arrhythmias are common. Some studies evaluated plausible mechanisms linking both events. Different physiopathologic pathways are involved in the pathogenesis of arrhythmias ${ }^{[6]}$.

- Hemodynamic effects

- $\quad$ Hypoxic trigger and Oxidative Stress

- $\quad$ Proinflammatory state

- Changes in autonomic nervous system

- Myocardial ischemia and changes in cardiac structure

\subsubsection{Hemodynamic effects}

The respiratory effort during apnoic events has the aims to overcome the obstruction of upper airway (the Mueller maneuver), but at the same time creates the conditions of negative intrathoracic pressure ${ }^{[7]}$. The "ab-estrinseco" stretch against the cardiac walls leads to augmented left ventricular afterload with impaired diastolic filling pressure. Repetitive forced inspiration during OSA with the resulting negative pressure in the chest cavity causes increased transmural 
gradients across cardiac chambers interfering with autonomic and hemodynamic stability. Infact, these hemodynamic features provoke also left atrial wall strein, increased atrial size with stretch-mediated channels changes and left ventricular hypertrophy and remodeling ${ }^{[2,6-8]}$.

\subsubsection{Hypoxic trigger and oxidative stress}

Apnea-induced hypoxemia represents harmful triggers for the heart through several physiopahtological mechanisms. During OSA there is an imbalance in gas exchange, thus $\mathrm{O}_{2}$ level is decrease also to cellular level. Intermittent hypoxia due to repetitive nightly upper airways occlusion increases the oxidative stress ${ }^{[2,7,8]}$. By molecular point of view myocytes react to this stress condition and lower $\mathrm{O}_{2}$ level with hypertrophy that creates the global effect of gradual deterioration of left ventricular filling leading to diastolic dysfunction ${ }^{[9]}$. Moreover, repetitive hypoxic events with subsequent reoxygenation seem to increase the susceptibility of heart to oxidative stress through mechanism of apoptosis and fibrosis based on modulated genetic adjustments ${ }^{[10]}$.

\subsubsection{Proinflammatory state}

Sleep deprivation is one of the effects of OSA that in combination with hypoxemia may be associated with increase of markers of inflammation ${ }^{[7]}$. In a study of Ryan et al. it is shown that in vitro there is an activation of pro-infiammatory factors due to events of intermittent hypoxia and conseguent reoxygenation ${ }^{[11]}$. Moreover there are evidences that in OSA patients serum levels of C-reactive protein ${ }^{[12]}$, plasma cytokines ${ }^{[13]}$ and leukocyte activation ${ }^{[14]}$ are increased. All of these detrimental changes in the pathway of flogosis linked to vasoactive substances release and to the aforementioned oxidative stress may to lead to endothelial dysfunction.

\subsubsection{Changes in autonomic nervous system}

During the sleep in patients with OSA there is an autonomic imbalance that creates the prerequisites for development of arrhythmias, both tachyarrhythmias and bradyarrhythmic events. The oscillations between parasympathetic and sympathetic preponderance provoke on the one hand bradycardia and/or pauses (when vagal tone rules, the diving reflex) on the other hand shortening of atrial refractory period, increase in ventricular ectopy burden (when sympathetic nerve activity surges) ${ }^{[2,6]}$.

\subsection{Myocardial ischemia and changes in cardiac structure}

The continuous nightly changes in patients suffered from OSA create a cascade of effects with a remarkable impact on myocardial substrate and cardiac structure. Indeed intermittent hypoxia and sympathetic hyperactivation in combination with fluctuations in blood pressure, heart rate and chest pressure lead to augmented myocardial oxygen consumption and reduced oxygen supply. The consequences could lead to myocardial damage and fibrosis contributing diastolic disfunction and scar as a substrate for arrhythmias, such as structural and electrical remodeling ${ }^{[6,8]}$.

\section{Focus on bradyarrhythmias}

Since 1982 there has been several description of the relationship between cardiac arrhythmias, conduction disorders and obstructive sleep apnea ${ }^{[15]}$. Although the link between obstructive apnoic events and conduction disturbances in adults remains controversial, bradyarrhythmic events are more common in subjects with obstructive sleep apnea than in healthy one. In the Sleep Heart Health Study even if statistically not significative the prevalence of conduction delay arrhythmias was higher in patients with SDB than in that one without ${ }^{[16]}$. Electrophysiological studies showed normal or pseudonormal parameters of sinus node and atrioventricular conduction in patients with OSA and ventricular asystole ${ }^{[17]}$. Simantirakis et al. in a prospective, observational study found that in patients with moderate-severe OSA there was higher prevalence of cardiac pauses $>3$ sec and bradycardic events $<40$ bpm monitored by implatable loop recorder ${ }^{[18]}$. Data from the European Multi-Center Polysomnography showed a high prevalence of sleep apnea syndrome in patients with pacemakers ${ }^{[19]}$. Regarding bradyarrhythmias and OSA involvement some mechanisms are explained by the resulting hypoxemia of apnoic events and an increase in vagal tone rather than a consequence of fixed structural disease of the conduction system ${ }^{[20,21]}$. Reduced oxygen levels due to recurrent apnoic events elicit the diving reflex with a subsequent cardiac vagal response 
characterized often by bradycardia but, in a minority of case in OSA patients atrioventricular, block and asystole may develop ${ }^{[7,22]}$. The heart rate response to obstructive events may be different in individuals because of the variability in the severity of hypoxia, chemosensitivity and their impact on the vagal-sympathetic balance ${ }^{[22]}$. These findings leave open the question about the close link between OSA and heart disease, highlighting if the impact of apnoic events is critical on heart rhythm or if OSA and arrhythmias may be simply sequelae of the underlying cardiac pathology. The role of the OSA treatment by CPAP during the night values these observations. In the aforementioned studies, such as in this case series, it is found that CPAP therapy significantly decreased sinus bradycardia and sinus pauses.

\section{Conclusion}

Nowadays several data suggest that OSA should be included among cardiovascular risk factors. Due to the key role of OSA in heart disease, chiefly arrhythmias, the increasing prevalence of OSA and cardiac comorbidities in general population, the poor quality of sleep and life and the poor outcome of the two combined conditions, and above all the potential beneficial effects of nightly treatment by CPAP, every physician should suspect the close link between bradyarrhythmias and OSA by detecting its early typical symptoms. Every patient with bradyarrhythmias, especially in the presence of signs and symptoms of OSA (even if only typical anthropometric features are present), should undergo polysomnography, although the optimal screening tools for OSA in patients with bradycardia have been not established yet. CPAP treatment, by now, is important in order to eliminate apneic events and at the same time to regulate cardiac rhythm balance.

\section{References}

[1] Peppard PE, Young T, Barnet JH, et al. Increased Prevalence of Sleep Disordered Breathing in Adults. Am J Epidemiol. 2013; 177: 1006-14. PMid:23589584 http://dx.doi.org/10.1093/aje/kws342

[2] Rossi VA, Stradling JR, Kohler M. Effects of obstructive sleep apnoea on heart rhythm. Eur Respir J. 2013; 41: $1439-51$. PMid:23258782 http://dx.doi.org/10.1183/09031936.00128412

[3] Kandel ER, Schwartz JH, Jessell TM. Principi di Neuroscienze. III ed. 2000; 47: 924-35.

[4] Berry RB1, Budhiraja R, Gottlieb DJ, et al. American Academy of Sleep Medicin e. Rules for Scoring Respiratory Events in Sleep: Update of the 2007 AASM Manual for the Scoring of Sleep And Associated Events. Journal of Clinical Sleep Medicine. 2012 Oct 15; 8(5): 597-619. PMid:23066376

[5] Parati G, Lombardi C, Narkiewicz K. Sleep apnea. Epidemiology, pathophysiology, and realtion to cardiovascular risk. Am J Physiol Regul Integr Comp Physiol. 2007; 293: R1671-83. PMid:17652356 http://dx.doi.org/10.1152/ajpregu.00400.2007

[6] Sahadevan J, Srinivasan D. Treatment of obstructive sleep apnea in patients with cardiac arrhythmias. Curr Treat Options Cardiovascular Med. 2012; 14: 520-28. PMid:22923098 http://dx.doi.org/10.1007/s11936-012-0201-x

[7] Sleep apnea and cardiovascular disease: an American Heart Association/american College Of Cardiology Foundation Scientific Statement from the American Heart Association Council for High Blood Pressure Research Professional Education Committee, Council on Clinical Cardiology, Stroke Council, and Council On Cardiovascular Nursing. In collaboration with the National Heart, Lung, and Blood Institute National Center on Sleep Disorders Research (National Institutes of Health). Somers VK, White DP, Amin R, et al. American Heart Association Council for High Blood Pressure Research Professional Education Committee, Council on Clinical Cardiology; American Heart Association Stroke Council; American Heart Association Council on Cardiovascular Nursing; American College of Cardiology Foundation. Circulation. 2008 Sep 2; 118(10): 1080-111. PMid:18725495 http://dx.doi.org/10.1161/CIRCULATIONAHA.107.189420

[8] Filgueiras-Rama D, Arias MA, Iniesta A, et al. Atrial arrhythmias in obstructive sleep apnea: underlying mechanisms and implications in the clinical setting. Pulm Med. 2013 Apr; 2013: 426758. http://dx.doi.org/10.1155/2013/426758

[9] Hedner J, Ejnell H, and Caidahl K. Left ventricular hypertrophy independent of hypertension in patients with obstructive sleep apnoea. Journal of Hypertension. 1990; 8(10): 941-46. PMid:2174947 http://dx.doi.org/10.1097/00004872-199010000-00009

[10] Hoffmann MS1, Singh P, Wolk R, et al. Microarray studies of genomic oxidative stress and cell cycle responses in obstructive sleep apnea. Antioxid Redox Signal. 2007; 9(6): 661-9. PMid:17511582 http://dx.doi.org/10.1089/ars.2007.1589 
[11] Ryan S1, Taylor CT, McNicholas WT. Selective activation of inflammatory pathways by intermittent hypoxia in obstructive sleep apnea syndrome. Circulation. 2005 Oct 25; 112(17): 2660-7. PMid:16246965 http://dx.doi.org/10.1161/CIRCULATIONAHA.105.556746

[12] Shamsuzzaman AS, Winnicki M, Lanfranchi P, et al. Elevated C-reactive protein in patients with obstructive sleep apnea. Circulation. 2002; 105: 2462-64. PMid:12034649 http://dx.doi.org/10.1161/01.CIR.0000018948.95175.03

[13] Ohga E, Tomita T, Wada H, et al. Effects of obstructive sleep apnea on circulating ICAM-1, IL-8, and MCP-1. J Appl Physiol. 2003; 94: 179-184. PMid:12391099

[14] Dyugovskaya L, Lavie P, Lavie L. Increased adhesion molecules expression and production of reactive oxygen species in leukocytes of sleep apnea patients. Am J Respir Crit Care Med. 2002; 165: 934-39. PMid:11934717 http://dx.doi.org/10.1164/ajrccm.165.7.2104126

[15] Miller WP. Cardiac arrhythmias and conduction disturbances in the sleep apnea syndrome. Prevalence and significance. Am J Med. 1982 Sep; 73(3): 317-21. http://dx.doi.org/10.1016/0002-9343(82)90716-1

[16] Mehra R, Benjamin EJ, Shahar E, et al. Sleep Heart Health Study. Association of nocturnal arrhythmias with sleep-disordered breathing: The Sleep Heart Health Study. Am J Respir Crit Care Med. 2006 15; 173(8): 910-16.

[17] Grimm W, Hoffmann J, Menz V, et al. Electrophysiologic evaluation of sinus node function and atrioventricular conduction in patients with prolonged ventricular asystole during obstructive sleep apnea. Am J Cardiol. 1996; 77: 1310-14. http://dx.doi.org/10.1016/S0002-9149(96)00197-X

[18] Simantirakis EN, Schiza SI, Marketou ME, et al. Severe bradyarrhythmias in patients with sleep apnoea: the effect of continuous positive airway pressure treatment: a long-term evaluation using an insertable loop recorder. Eur Heart J. 2004 Jun; 25(12): 1070-6. PMid:15191779 http://dx.doi.org/10.1016/j.ehj.2004.04.017

[19] Garrigue S, Pépin JL, Defaye P, et al. High prevalence of sleep apnea syndrome in patients with long-term pacing: the European Multicenter Polysomnographic Study. Circulation. 2007 Apr 3; 115(13): 1703-9. PMid:17353437 http://dx.doi.org/10.1161/CIRCULATIONAHA.106.659706

[20] Somers VK, Dyken ME, Clary MP, et al. Sympathetic neural mechanisms in obstructive sleep apnea. J Clin Invest. 1995; 96:1897-904. PMid:7560081 http://dx.doi.org/10.1172/JCI118235

[21] Hedner J, Ejnell H, Sellgren J, et al. Is high and fluctuating muscle nerve sympathetic activity in the sleep apnoea syndrome of pathogenic importance for the development of hypertension. J Hypertens. 1983; Suppl 6: S529-31.

[22] Leung RS. Sleep-disordered breathing: autonomic mechanisms and arrhythmias. Prog Cardiovasc Dis. 2009 Jan-Feb; 51(4): 324-38. PMid:19110134 http://dx.doi.org/10.1016/j.pcad.2008.06.002 